\title{
Minority Students' Characteristics of Foreign Language Learning Anxiety
}

\author{
Zehai Liu \\ College of International Education \\ Jishou University \\ Jishou, China 416000
}

\begin{abstract}
Anxiety is common in the process of foreign language learning. By using a questionnaire, this research aims at investigating the general levels and structural characteristics of minority middle school students' foreign language learning anxiety in a minority area of Western Hunan in China. The results show that the total levels of English learning anxiety of the students in this remote region are comparatively high, with obvious individual differences. In situation dimensions, the mean score of classroom anxiety was lower than that of communication anxiety; while in personality dimensions, students have high anxiety in the aspects of fear of negative evaluation and tolerance of ambiguity.
\end{abstract}

Keywords-minority students; language learning anxiety; characteristics; countermeasure

\section{INTRODUCTION}

Generally speaking, anxiety is defined as a response similar to worry. In defining particular anxiety, researchers have made different statements. Oxford (1999) defines language anxiety not "as a general state, but as a feeling of apprehension produced when learners communicate in a target language". Horwitz \& Young (1991) defines it as "a feeling of tension, apprehension and nervousness associated with the situation of learning a foreign language". Related researches show that anxiety could interfere with "the acquisition, retention and production of a new language".

Foreign language learning is a real challenge to students in minority areas. Liu Xuehui (2009) believes "the nervous and fearful psychology of Chinese middle school students in foreign language learning is very obvious". This research aims at investigating the English learning anxiety state by a sample of minority middle school students in Hunan Province of China, trying to find the general characteristics of language learning anxiety among minority middle school students and helping overcome negative influence of anxiety effectively and further improving their English proficiency.

\section{DESCRIPTION AND DISCUSSION OF THE STUDY}

This research aims at examining and analyzing the general levels and structural characteristics of minority middle school students' foreign language learning anxiety in Western Hunan (a minority area of the province) of China, and the relationship between students' English grades and anxiety.

\section{A. Subjects}

With random sampling, 401 junior middle school students are sampled. They are mostly between the ages of 13 to 15 years old and come from 3 different middle schools in the remote regions of Hunan province in China.

\section{B. Instruments}

This research was conducted by creating a questionnaire. Mainly consulting Horwitz et al (1986) "The Foreign Language Classroom Anxiety Scales (FLCAS)" and combining with our own experience and intuition both as foreign language learners and teachers, we designed a questionnaire "Questionnaire of Anxiety of Middle School Students' English Learning". As anxiety is a mood that is controlled by situation factors and personality factors, we measured the concept of foreign language anxiety (FLA) by including the two levels of situation and personality. In the situation levels, with reference to relevant literature and based on the foreign language characteristics of our students, FLA is divided into three dimensions: classroom anxiety, communication anxiety and test anxiety. On personality level, we include fear of negative evaluation, lack of tolerance of ambiguity, and ill self-concept and lack of self-confidence in foreign language learning.

\section{Data Collection and Analysis Procedure}

This investigation was conducted by those middle school teachers in the eighteen classes of the three middle schools in Jishou from May $10^{\text {th }}$ to $14^{\text {th }}, 2018$. The teachers were required to tell the students of the scientific purpose of the survey and inform them that there were no right or wrong answers, that the test wouldn't be corrected by their teachers, and that the investigation results (which would be kept in complete confidence) would not affect their grades or anyone's opinions towards them, and were also to help them learn more about how to learn English more effectively. Then the questionnaires were administered during the morning class, and took the students about 30 minutes to complete. Believing that the survey would help them become better language learners, the students showed great interest in it and took it seriously. 410 copies of the questionnaire were 
distributed, and 401 valid responses were collected. Among them were 133 from first-year students, 134 from secondyear students, 134 from third-year students. The data was processed using SPSS16.0.

\section{Discussion of the Study}

1) The total levels and group differences of middle school students' foreign language classroom anxiety in the underdeveloped minority region of western hunan (sampled in the city of Jishou) of China: While calculating the mean of each question, we first added up all the scores of the 401 students, and then divided by 401 ; the result was the mean of the question. While calculating the percentage, we first added up the number of the students who chose the score, then divided by 401 . We could find that the means of eleven questions are higher than medium anxiety score 3.00. Among them two questions are related to listening practice, two other questions with test anxiety, three questions with speaking activities, three questions with classroom anxiety, and one question with self-concept. In short, five questions have a relationship with communication apprehension. From our analysis of the eleven questions of the lowest anxiety scales, we also found some significant results. Students experienced more pleasure in English class than we expected before the investigation. And that they are confident in learning English well even though they sometimes feel nervous in English class.

2) Main structural characteristics of students' foreign language anxiety in minority region:

a) Situation dimensions: Diagram 1 shows the scores of partial items on three situation dimensions: classroom anxiety, communication comprehension and test anxiety. Each item was calculated on a 5-point scale. The positive questions were calculated by 1-5 scale points, from "strongly disagree" to "strongly agree", while the negative ones were calculated by $1-5$ scale points from a reversal order.

From "Table I", it can be seen that the scores on most communication anxiety items are high. When communicating with a foreign language, especially in oral communication apprehension, we must react quickly and are consistently exposed to the evaluations of others. In such a strong self-threatening situation, the participants are likely to experience the feeling of anxiety. When anxiety does arise relating to the use of foreign language, it seems to be restricted mainly to speaking and listening reflecting learners' apprehension at having to communicate spontaneously in foreign language (Horwitz, Horwitz, \& Cope 1986). Anxiety is most often focused on listening and speaking, with difficulty in speaking in class being the most common complaint of anxious students. Owing to the fact that New Curricula Syllabus pays more attention to the skills of communication, it might increase students' anxiety levels to a great extent than before. If our teachers are unable to master the spirit of the new Curricula Syllabus to encourage students to practice English in class, and fail to diversify their teaching methods to arouse students' interests in speaking English, the students might show less interest in English and experience higher anxiety. The diagram also shows that reading anxiety was lower than listening and speaking anxiety. Students experienced anxiety when they met with many new words in reading and didn't understand the article well. But why are reading anxiety levels lower than listening and speaking ones? This might be because of the characteristics of reading itself, e.g. one can control the reading speed; they can reread the article and won't be evaluated directly by others, etc. We also found some satisfactory results. Some of our students dare to speak English loudly in class and are not afraid of making mistakes or being laughed at; while in previous years, students always kept silent in class no matter how you encouraged them to speak English.

The mean score of classroom anxiety was lower than that of communication. In current foreign language teaching, teachers are required to pay more attention to the training of students' communicative abilities, and to give them more time and chance to speak and listen to English in class, whereas in the past teachers were asked to focus their attention on language points, and to explain the meanings of new words and text in details. In contrast with the past, our students experienced higher classroom anxiety than ever before. They had to keep on drilling their oral English even if this might increase their classroom anxiety. They were afraid that their teachers would ask those questions that they hadn't prepared for in advance and felt even afraid when they couldn't grasp their teachers' meaning even after being corrected. Not daring to volunteer to put up their hands and answer a question was another manifestation of high classroom anxiety. In short, students' classroom anxiety originated from their fear of communication with teachers and classmates (oral performance in front of the class) to a great extent. What is surprising is that, even if students were burdened with higher classroom anxiety, most students felt no obvious pressure to prepare for English class and experienced some degrees of satisfaction.

Anxiety also shows up in other situations such as tests. Test anxiety is "the tendency to become alarmed about the consequences of inadequate performance on a test or other evaluation", regardless of whether the fears are realistic. Students with test anxiety frequently experience cognitive interference (Sarason 1984) and have a difficult time focusing on the task at hand. Our investigations indicated that total scores of test anxiety were very high, and some items showed high anxiety score. For example, during the process of preparation for examination, they wanted to learn every important language point by heart. After examination, they were afraid of getting bad results. Though they wouldn't get nervous in examination, they couldn't concentrate on the task. When they wouldn't handle with the information of test to the best of their ability, they would feel very nervous. 
TABLE I. SCORES OF EACH ITEM IN SITUATION DIMENSIONS

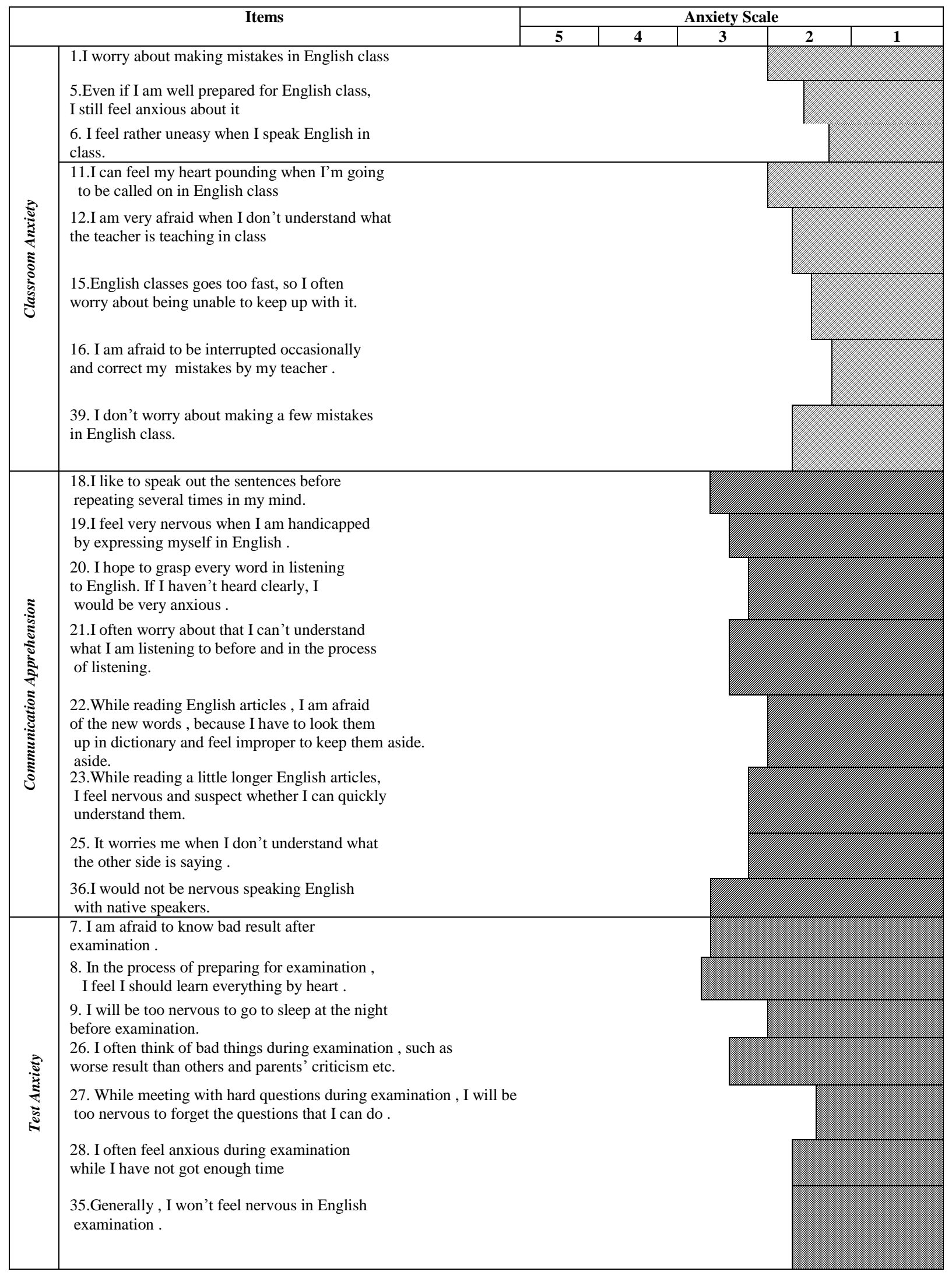


TABLE II. SCORES OF EACH ITEM IN PERSONALITy DiMENSIONS

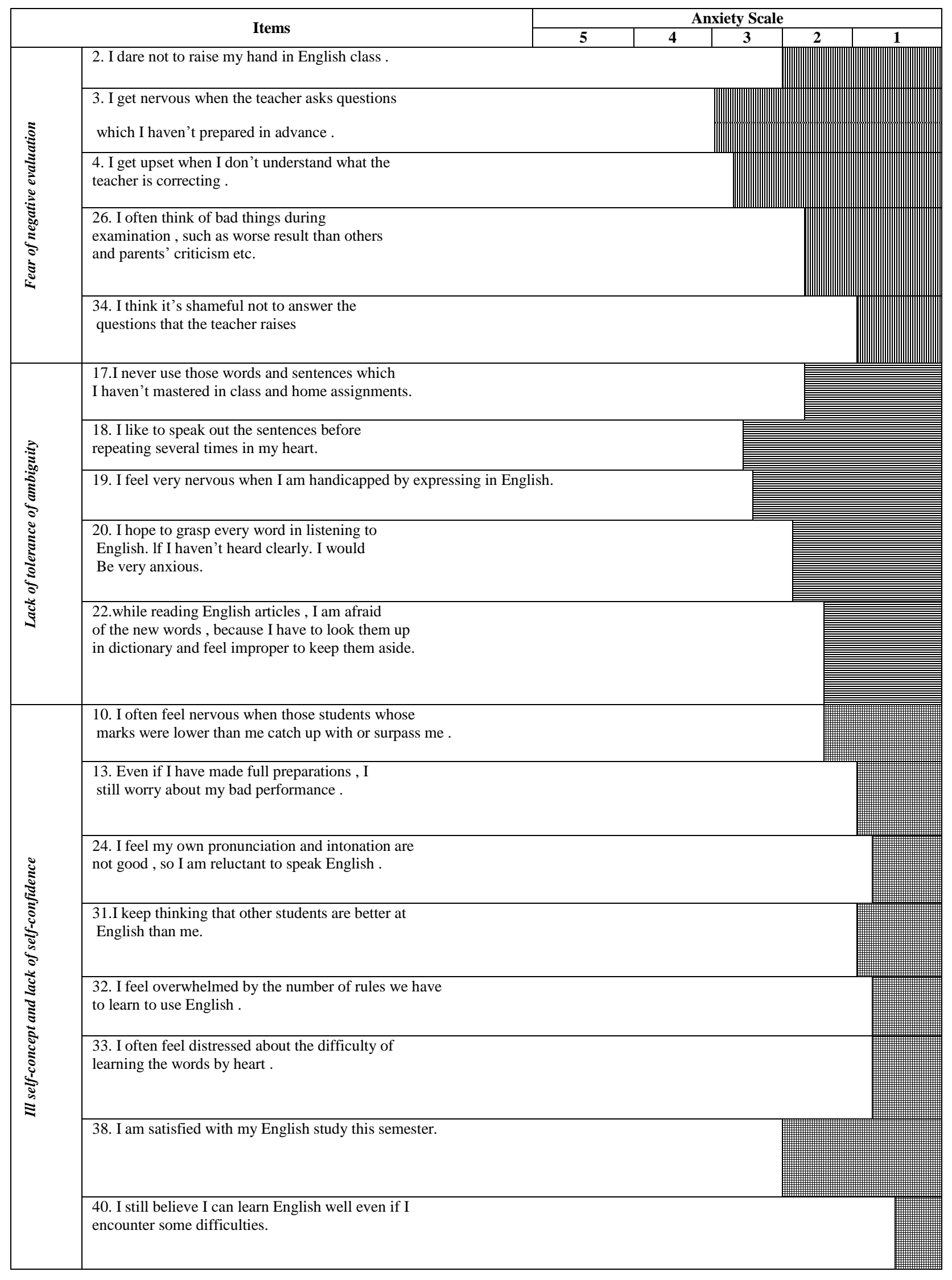


b) Personality dimensions: "Table II" showed the partial items scores of the three personality dimensions: fear of negative evaluation, lack of tolerance of ambiguity, and ill self-concept of foreign language learning and lack of selfconfidence.

The scores of the items concerning "fear of negative evaluation' was high. It is a psychological weakness of our remote region students" foreign language learning. Foreign language learning is full of evaluations. Whether in classroom learning, in communicating with others or in taking a test, students are always exposed to evaluation situations. Fear of negative evaluation means that one is afraid of being evaluated by others and worries that others will make a negative evaluation of him. Our investigation showed that those who paid too much attention to others' views might minimize these disadvantage factors to evaluation, trying to avoid evaluation on purpose or leave ahead of time. When doing pair or group oral practice of communicating with others, they usually don't speak at first, but keep silent and try not to interrupt others. The typical behavior is smiling, nodding politely and just listening to others.

The scores of the items relating to 'tolerance of ambiguity' were also high. Tolerance of ambiguity is the acceptance of confusing situations. Foreign language learning has a great deal of ambiguity about meanings, referents and pronunciation. And this can often raise language anxiety. Therefore, a degree of tolerance of ambiguity is essential for language learners. Students who are able to tolerate moderate levels of confusion are likely to persist longer in language learning than students who are overly frightened by the ambiguities inherent in learning a new language.

Owing to the fact that they have mainly been exposed to traditional mechanical training methods, our Chinese students have formed a strong 'monitor' sense, paying too much attention to the correctness and preciseness of language forms; and looked on some unavoidable uncertainty as a threat to them, hence produced an uneasy and nervous mood. Furthermore, current foreign language teaching pays high attention to students' listening and speaking ability, yet students still have difficulty in understanding English in low or normal speed. They worried about and even felt anxious when they couldn't catch the meaning of listening material. Among reading activities, students experienced highest anxiety in a cloze text. In a cloze text, retrieving the language fragment is practical to handling information. The higher language proficiency one has, the higher tolerance of broken information one can hold. But cloze test involves not only broken information, but also the degree of difficulty of the language itself. While doing this cloze test "psychology puzzle game", the students' degrees of anxiety influence their grades greatly.

The scores of most "ill self-concept of foreign language learning and lack of self-confidence" items were high, too. There existed two situations: one case was that part of the students (mainly low-grade students) did think that their foreign language learning abilities were very poor, lacked self-efficacy of foreign language learning and hence lacked of self-confidence. The other case was that some students worried that other students would catch up with or surpass them, no matter how complete were the preparations they made. Some other students worried about their unsatisfying performance, and weren't satisfied with their learning. We think we should find students' questions of positive selfconcepts and lack of confidence in foreign language learning. This situation has a close relationship with teachers' attitudes and evaluation methods. To our satisfaction, they still believe that they can learn English well, and are full of confidence about the future.

\section{CONCLUSION}

In this study, the following conclusions are reached: The students' anxiety about oral communication activities was more obvious than that in language knowledge learning and tests. Anxiety had obvious negative relationship with English grades in all items (listening, speaking, reading and language knowledge). This showed that anxiety was a disadvantage factor for improving English grades and that it was an obstacle to the improvement of oral communicative proficiency.

\section{REFERENCES}

[1] R. Ellis, The Study of Second Language Acquisition, Oxford: Oxford University Press, 2014.

[2] S. D.Krashen, The Input Hypothesis: Issues and Implications. London: Longman, 1985.

[3] P. D.MacIntyre, \& R. C. Gardner, The Subtle Effects of Language Anxiety on Cognitive Processing in the Second Language, Language Learning, vol.44: 283-305,1994.

[4] G. P. Park, \& B. F. French, Gender differences in the foreign language classroom anxiety scale, System, vol.41, 462-471, 2018.

[5] T. Scovel, The Effect of Affect in Foreign Language Learning: A Review of the Anxiety research. Language Learning, vol.28: 129-142, 2017.

[6] P. Skehan, A Cognitive Approach to Language Learning, Oxford: Oxford University Press, 2017.

[7] B. Spolsky, Conditions for Second Language Learning. Oxford: Oxford University Press, 1989. 